\title{
The burning question: does fire affect habitat selection and forage preference of the black rhinoceros Diceros bicornis in East African savannahs?
}

\author{
T. Michael Anderson, Philbert M. Ngoti, Mawazo L. Nzunda \\ Daniel M. Griffith, James D. M. Speed, Frode Foss $\varnothing$ y \\ EIVIN RøskAfT and Bente J. GRAAE
}

\begin{abstract}
The conservation of threatened species requires information on how management activities influence habitat quality. The Critically Endangered black rhinoceros Diceros bicornis is restricted to savannahs representing c. $5 \%$ of its historical range. Fire is used extensively in savannahs but little is known about how rhinos respond to burning. Our aim was to understand rhino responses to fire by studying habitat selection and foraging at multiple scales. We used resource selection functions and locations of 31 rhinos during 2014-2016 to study rhino habitat use in Serengeti National Park, Tanzania. Rhino selectivity was quantified by comparing forage consumption to plant species availability in randomly sampled vegetation plots; rhino diets were subsequently verified through DNA metabarcoding analysis of faecal samples. Rhino habitat use was a unimodal function of fire history, with highly occupied sites having fire frequencies of $<0.6$ fires/year and maximum occupancy occurring at a fire frequency of 0.1 fires/year. Foraging stations had characteristic plant communities, with 17 species associated with rhino foraging. Rhinos were associated with, and disproportionately consumed, woody plants, forbs and legumes, all of which decreased in abundance with increasing fire frequency. In contrast to common management practices, multiple lines of evidence suggest that the current fire regime in the Serengeti negatively influences rhino habitat use and foraging and that frequent fire limits access of rhinos to preferred forage. We outline a conceptual
\end{abstract}

T. Michael Anderson (Corresponding author) Department of Biology, Wake Forest University, Winston-Salem North Carolina, 27106, USA

E-mail anderstm@wfu.edu

Philbert M. Ngoti ${ }^{*}$, Frode Fossøy $\dagger$, Eivin Røskaft and Bente J. Graae Department of Biology, Norwegian University of Science and Technology, Trondheim, Norway

Mawazo L. Nzunda Serengeti Wildlife Research Centre, Seronera, Tanzania

Daniel M. Griffith Forest Ecosystems and Society, Oregon State University, Corvallis, Oregon, USA

James D. M. Speed Department of Natural History, Norwegian University of Science and Technology, Trondheim, Norway

*Also at: Tanzanian National Parks, Arusha, Tanzania

$\dagger$ Also at: Norwegian Institute for Nature Research, Trondheim, Norway

Received 12 September 2017. Revision requested 31 January 2018.

Accepted 26 February 2018. First published online 17 August 2018. model to guide managers and conservationists in the use of fire under variable habitat conditions.

Keywords Browser foraging, Diceros bicornis, fire frequency, habitat selection, resource selection functions, savannah, Serengeti National Park, spatial occupancy model Supplementary material for this article is available at https:// doi.org/10.1017/So030605318000388

\section{Introduction}

T erbivore foraging is hierarchical over a range of spatial 1 scales: individuals select patches within landscapes, where to forage and what plants to consume within patches (e.g. Bailey et al., 1996; Searle et al., 2005). Optimal foraging models suggest that herbivores integrate information on resource quality and quantity (Hopcraft et al., 2012), energy intake rates (Fryxell et al., 2004), home ranges or territories (Mitchell \& Powell, 2012) and predation risk (Valeix et al., 2009) when selecting habitat patches in a heterogeneous landscape (e.g. Owen-Smith et al., 2010).

For rare or threatened species, a thorough understanding of how individuals identify and select habitat and forage is required for successful management and conservation. This is especially true when management activities, such as fencing, burning, mowing or chemical application, can be targeted at increasing or restoring habitats or forage that may encourage population growth and stability. In African savannahs, natural resource managers use fire as a tool to increase nutrient rich forage for grazers (e.g. Parrini \& Owen-Smith, 2010), reduce bush encroachment (Dalle et al., 2006) and control ticks and diseases (e.g. Trollope, 2011). Fire can increase nutrient concentrations in regrowing grasses (Anderson et al., 2007) and the ratio of grass to woody plants (Holdo et al., 2009), both of which favour grazing herbivores. Savannahs also harbour a diverse community of browsing herbivores, but the impact of fire on browser forage quality and quantity is less well understood (but see Ferwerda et al., 2006).

The black rhinoceros Diceros bicornis is a large-bodied savannah browser that uses hind-gut fermentation for digestion. Illegal poaching during the 2oth century decimated black 
rhino populations across Africa; they are now one of the most threatened large mammals (Emslie, 2012). Prior to 1960 black rhinos were abundant in protected areas throughout their native range and numbered in the hundreds of thousands across Africa (Emslie, 2012). In Serengeti National Park, in northern Tanzania, population estimates in the late 1970 s were $400-700$ (Frame, 1980). By the early 1980 os poaching had reduced the population to 10 individuals (Borner, 1981; Metzger, et al., 2007). Today, $<50$ survive, under heavy surveillance.

Habitat selection by rhinos is positively related to vegetation type, such as thicket and dense savannah for black rhinos in South Africa and forest for Sumatran rhinos, and negatively related to human settlements and roads (Odendaal-Holmes et al., 2014; Pusparini et al., 2015). Although fire is an important management tool for African savannahs, little is known about how fire influences the black rhino's use of the landscape. Emslie \& Adcock (1994b) called fire 'one of the most important influences on black rhino habitat', but data on how fire influences rhino spatial occupancy, habitat selection and foraging is scarce. Rhinos in the Ngorongoro Crater fed on charred and resprouting plants in recent burns, suggesting that burning may increase the availability of essential nutrients (Goddard, 1968), and black rhinos in Hluhluwe and Umfolozi game reserves in South Africa preferred recently burnt areas and selected burnt twigs of Acacia, suggesting that burning is beneficial (Emslie \& Adcock, 1994a). Consequently, we hypothesized that fire would increase the nutritive quality of resprouting tissues and keep woody plants within an accessible height $(<2.5 \mathrm{~m}$; e.g. Kotze \& Zacharias, 1993). However, we also considered the alternative hypothesis that fire would reduce the abundance of woody plants and forbs preferred by rhinos in favour of fire-tolerant grasses.

Here we explore fire effects on rhino habitat use and on plant species selectively consumed by rhinos across a range of scales. We adopted a hierarchical approach that investigated rhino selectivity from the landscape scale to the scale of the individual animal and plant species (Fig. 1). At the scale of the landscape, we aimed to identify landscape features, fire regimes (i.e. frequency) and vegetation characteristics that predict rhino habitat use over multiple seasons. At the scale of foraging stations, we asked if rhino foraging was significantly associated with particular plant species. Within foraging stations, we asked if rhinos showed preferences for particular plant species or, alternatively, if they fed indiscriminately. Finally, if rhinos were associated with particular plant species, we asked how their abundance varied with fire frequency.

\section{Methods}

\section{Ecosystem and study area}

Our study was conducted in Serengeti National Park, part of the $30,000 \mathrm{~km}^{2}$ Serengeti ecosystem between northern

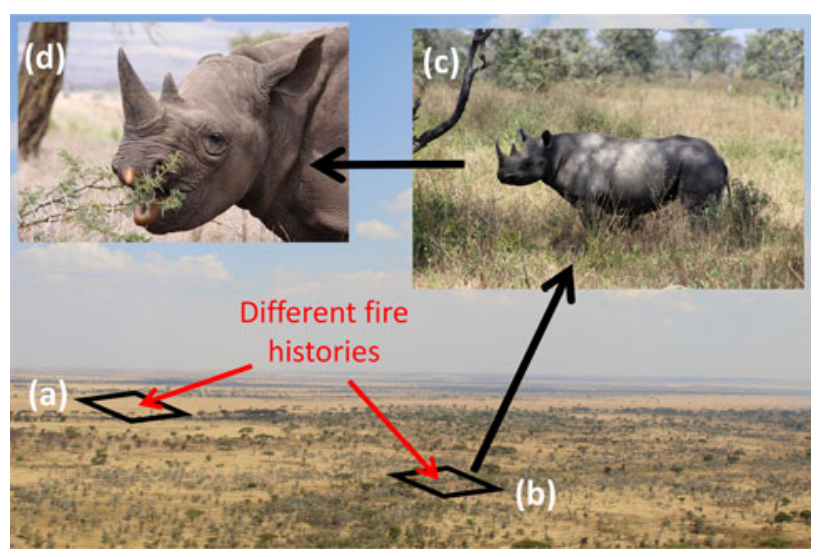

FIG. 1 The hierarchical and scale-dependent nature of black rhinoceros Diceros bicornis habitat and forage selection. Rhinos select patches within the landscape, foraging stations within patches and plants for consumption within foraging stations. (a) A grassy site with a history of frequent fire; (b) a woodland site with a history of low fire frequency; (c) a foraging station selected by rhinos within a heterogeneous landscape; (d) rhino selecting low-growing Acacia branches within a given foraging station (background photograph and (c) courtesy of Luisa Arenado; (d) courtesy of Phil Perry).

Tanzania and southern Kenya. Serengeti vegetation is a mix of edaphic grassland and Acacia-Commiphora deciduous woodlands (White, 1983). A large region of edaphic grassland in the south-east of the Park (i.e. the Serengeti plains) lies over ash-derived volcanic soils (de Wit, 1978). The remaining two-thirds of the Park, to the north and west, are typical wooded savannah habitat overlaying granitic and gneissic soils (Jager, 1982). Our study focused on a population of c. 40 rhinos in the Moru region of the Serengeti, between the Serengeti plains to the east and wooded hills to the west. Detailed records and observations of individual rhinos, including identity, behavior and spatial location, were collected opportunistically by Tanzanian National Parks anti-poaching rangers. We used locations of rhinos during a 2-year period (2014-2016) to delineate the $3433 \mathrm{~km}^{2}$ Moru study area.

\section{Habitat selection}

We used resource selection functions (e.g. Manly et al., 2002) to model rhino habitat use in relation to vegetation, topography and fire history. A common approach for resource selection functions, and one that is implemented here, is to use logistic regression with utilized and unutilized sites as binomial response variables (i.e. $1=$ utilized, $\mathrm{o}=$ unutilized) and environmental variables associated with each location as predictors (e.g. Boyce et al., 2003; Johnson et al., 2004; Shafer et al., 2012). Utilized habitat was based on 1,740 locations for 31 different rhinos recorded with a GPS between 26 June 2014 and 5 May 2016. The available (but unutilized) 
TABLE 1 Results of AIC model selection (ordered by $\triangle \mathrm{AIC}$ ) for resource selection functions predicting occupancy of 31 rhinoceroses Diceros bicornis during 2014-2016.

\begin{tabular}{lrlll}
\hline Model & $\Delta$ AIC $^{1}$ & df & Description & Variables $^{2}$ \\
\hline 9 & 0.0 & 8 & Main effects with intermediate disturbance & Slope + TWI + NDVI + Fire + (Fire $\times$ Fire $)$ \\
8 & 3.9 & 7 & Main effects & Slope + TWI + NDVI + Fire \\
10 & 5.4 & 8 & Main effects with intermediate resources & Slope + TWI + Fire + NDVI + NDVI $\times$ NDVI) \\
6 & 20.2 & 5 & Topography & Slope \\
7 & 142.7 & 5 & Water + resources & TWI + NDVI \\
5 & 147.0 & 5 & Disturbance & Fire + (Fire $\times$ Fire $)$ \\
4 & 173.3 & 4 & Disturbance & Fire \\
1 & 237.3 & 3 & Null model & $\sim 1$ \\
2 & 238.0 & 4 & Resources & NDVI \\
3 & 240.0 & 5 & Resources & NDVI $+($ NDVI $\times$ NDVI $)$ \\
\hline
\end{tabular}

${ }^{1}$ Difference in AIC from best model.

${ }^{2}$ TWI, topographic wetness index, NDVI, normalized difference vegetation index; Fire, fire frequency (fires/year); $\sim 1$, the intercept only model.

habitat was identified by randomly selecting three points within $10 \mathrm{~km}$ of each rhino observation, representing an appropriate ratio of utilized to available habitat (Northrup et al., 2013). Areas above $1,750 \mathrm{~m}$ altitude (e.g. hilltops) were excluded from the available habitat because rhinos avoided these areas during the 2-year observation period. The $10 \mathrm{~km}$ distance was chosen for random point selection because it is half the maximum distance travelled in a single day by black rhinos in Namibia (Göttert et al., 2010).

Landscape variation in topography, vegetation greenness and fire history were extracted for each location using the raster package (Hijmans, 2016) in R 3.4.2 (R Development Core Team, 2017). Slope was estimated from a global $90 \mathrm{~m}$ digital elevation model (Jarvis et al., 2008). Topographic wetness index (TWI) was calculated from a hydrologically conditioned digital elevation model (Lehner et al., 2006). This index combines upslope area, flow direction and slope angle to estimate water accumulation at a point for a given precipitation (e.g. Sörensen et al., 2006). As an estimate of vegetation greenness, we created an 8-day near-infrared difference vegetation index (NDVI) using raw reflectance data collected during May 2000-April 2016 by NASA's Moderate Resolution Imaging Spectroradiometer (MODogGQ; Supplementary Material 1). NDVI represents standing plant biomass, with larger values representing more abundant and higher quality vegetation (Vermote \& Wolfe, 2015). The MODogGQ data were also used to create an 8-day fire product using algorithms developed by Dempewolf et al. (2007), from which we calculated fire frequency (Fire); i.e. the number of fires divided by the time period (16 years; Supplementary Material 1; Supplementary Figs $1 \& 2$ ).

To control for variation among individual rhinos and the temporal autocorrelation created by repeated sampling, we used mixed-model logistic regression (e.g. Gillies et al., 2006) with Slope, TWI, NDVI and Fire as fixed, main effects, and rhino identity (Rhino) and day (Date) as random effects in the model. Foraging opportunities may be limited by high fire frequency, which reduces woody biomass, and low fire frequency, which allows trees to outgrow the maximum browse height for rhinos (c. $2 \mathrm{~m}$ ). Thus, in addition to linear terms, we also included models with quadratic terms to allow for the hypothesis that rhinos favoured habitats with intermediate values of Fire or NDVI. The model was fit using the glmer command in the R package lme4 (Bates et al., 2015) assuming a binomial response and fixed predictors zero-scaled prior to modeling. Ten candidate models were identified, emphasizing combinations of topography, resource availability and fire (Table 1 ). The model with the smallest Akaike's Information Criteria (AIC) value was selected as the best explanation of the data; models within 2 AIC units were considered equivalent (e.g. Burnham \& Anderson, 2002).

\section{Forage selectivity}

Rhino forage selectivity was analysed at two spatial scales: Firstly, vegetation composition at rhino foraging stations was compared to randomly located plots. Secondly, we determined if the plant species consumed by rhinos within foraging stations were consumed preferentially or in proportion to their availability.

For the first scale, rhino foraging stations were identified opportunistically during June-August 2016 using the backtracking method (e.g. Oloo et al., 1994; Ganqa et al., 2005; van Lieverloo et al., 2009). Rhino foraging stations were observed, coordinates were recorded, and stations were relocated immediately after the location was vacated by the rhino. A total of 64 foraging stations were surveyed, representing 19 individual rhinos. Each foraging station consisted of a $4 \mathrm{~m}^{2}(2 \times 2 \mathrm{~m})$ plot in which ground cover of each plant species was quantified. To establish background forage availability, plant species composition was quantified at 60 sites that were randomly located across the study area. At 
each site the ground cover of each plant species was quantified in five $4 \mathrm{~m}^{2}$ plots, each separated by $20 \mathrm{~m}$, in a linear array. To ensure that background forage availability was adequately sampled across fire histories, 24 additional sites were randomly selected in areas with 1, 3, 5 or 15 years since the last fire. At each of these sites ground cover of each plant species was quantified in nine $4 \mathrm{~m}^{2}$ plots, arranged in two perpendicular arrays of five plots separated by $20 \mathrm{~m}$ each (with one shared center plot). In total, $5604 \mathrm{~m}^{2}$ plots were sampled. Cover data were summed, relativized and analysed with non-metric multi-dimensional scaling (NMDS) using the metaMDS command and Bray-Curtis distance in the $R$ package vegan (Oksanen et al., 2017); plant species in six or fewer plots across the dataset were removed prior to analysis. Models were estimated with 1, 2 and 3 axis solutions and up to 500 random starts to converge; the model with the fewest axes and stress $<0.2$ was accepted as the final model (McCune et al., 2002). We explored the relationship between environmental factors and NMDS axis scores with a mixed model linear regression using the lmer command in the $R$ package lme4; the best model was selected using AIC. Models included all main effect combinations of Slope, TWI and Fire. Subsequently, we conducted indicator species analysis using the multipatt command in the $R$ package indicspecies (De Cáceres \& Legendre, 2009), to investigate if individual plant species were statistically associated with rhino foraging stations. The species by plot matrix served as input data and plot type (either a rhino forage plot or not) as the cluster variable. We used the group-equalized indicator value (De Cáceres et al., 2010; option 'func. = IndVal.g' in $R$ ) for the analysis and determined statistical significance by species using permutation tests (option 'nperm $=999$ ' in $R$ ).

For the second scale, plant species within the 64 rhino foraging plots were inspected for evidence of rhino browsing by their distinct bite pattern relative to other ungulates (e.g. Oloo et al., 1994). The per cent browsed for each species was analysed relative to the availability of that species by calculating the type III Manly's selectivity index with the widesIII command in the $R$ package adehabitatHS (Calenge, 2006; Morrison et al., 2016). This index (Wiii) estimates resource selection individually for each animal assuming that resource availability (i.e. plant composition within the visited plots) is known (Manly et al., 2002). Plant species were assigned a selection index, with Wiii $=1$ indicating the plant was selected in proportion to its availability, Wiii $>1$ indicating positive selection and Wiii $<1$ indicating avoidance.

\section{Plant DNA identified from dung}

Rhino diet preferences were analysed via DNA metabarcoding (e.g. Kartzinel et al., 2015) by opportunistically collecting
TABLE 2 Logistic regression model coefficients for the best resource selection functions (model 9 in Table 1) predicting rhino habitat selection.

\begin{tabular}{lrlcr}
\hline Variable & Estimate & SE & \multicolumn{1}{l}{ P } & \multicolumn{1}{l}{ P } \\
\hline Intercept & -1.109 & 0.038 & -28.94 & $<0.0001$ \\
Slope & -0.622 & 0.086 & -7.2 & $<0.0001$ \\
TWI & 0.129 & 0.031 & 4.15 & $<0.0001$ \\
NDVI & 0.079 & 0.029 & 2.71 & 0.0068 \\
Fire & 0.063 & 0.089 & 0.709 & 0.4780 \\
Fire $\times$ Fire & -0.264 & 0.116 & -2.27 & 0.0232 \\
\hline
\end{tabular}

15 fresh dung samples from individuals observed defecating $(n=4)$ or found during foraging observations $(n=11)$. Samples were stored in $96 \%$ ethanol; prior to exportation and DNA metabarcoding, samples were exposed to air for c. 10 seconds to allow ethanol to evaporate and then packed in silica gel (Supplementary Material 1). Molecular libraries were used to identify the lowest possible taxonomic identity of plants in the samples (i.e. molecular operational taxonomic units or MOTUs). The number of sequences for each MOTU was divided by the total number of sequences per sample to obtain the relative read abundance and the taxonomic sample frequency was the frequency of each MOTU across all samples. Only MOTUs with taxonomic sample frequencies $\geq 5$ and relative read abundances $>2 \%$ were considered in the final analysis.

\section{Effect of fire on preferred forage}

We explored the effects of fire on plant species associated with rhino foraging using mixed model regression analysis with the lmer command in lmes and with the best model selected using AIC. As a response variable, we summed the relative cover of all plant species statistically associated with rhino foraging from the indicator analysis (i.e. with $\mathrm{P}<0.05$ from permutation tests). All models included Fire as a fixed predictor and Site as a random effect to control for the spatial association of plots nested within sites. Topography was analysed by including TWI and Slope as main and interaction effects in all pairwise combinations with Fire.

\section{Results}

Habitat selection The top model predicting rhino utilization of the landscape (Table 1) included landscape features (Slope and TWI), plant productivity (NDVI) and linear and quadratic terms for fire frequency (Fire). Relative to randomly sampled points, rhinos tracked productive green vegetation and occupied flat sites that accumulate moisture (Table 2). In addition, the quadratic Fire term indicates that rhinos selected landscape patches that burn at a relatively low frequency of $0.1 /$ year (i.e. one 


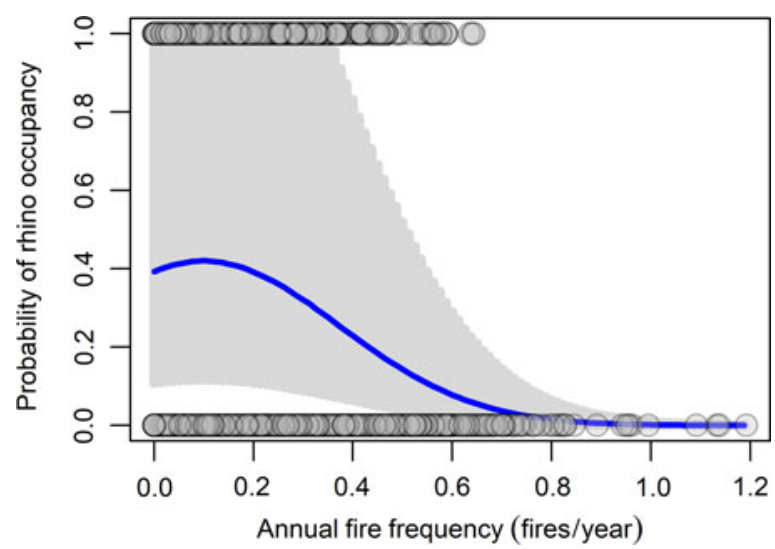

FIG. 2 Presence or absence of rhinos (grey dots) across values of fire frequency for rhino locations and randomly selected non-rhino points. The modelled response (line) shows the quadratic response of rhino occupancy to average annual fire frequency; grey shaded area shows the $95 \%$ prediction interval for the mean.

fire every 10 years; Fig. 2) and avoid frequently burnt sites (i.e. Fire $>0.6 /$ year).

Forage plots The best NMDS ordination had a three axis solution and final stress $=0.196$. NMDS axes 1 and 3 explained the most variation and showed that rhino foraging plots (Fig. 3) were compositionally distinct from much of the landscape; i.e. more positive on axes 1 and 3 than randomly sampled background plots (Fig. 3). Positive values on axis 1 were associated with large cover values of Indigofera basiflora, Bothriochloa insculpta, Eustachys paspaloides and Dolichos trilobus (Kendall's $\tau$ values $=0.38$, $0.32,0.28$ and 0.26 respectively; Supplementary Table 3). Positive values on axis 3 were characterized by plots with abundant cover of Pennisetum mezianum, Cymbopogon excavatus and Bothriochloa insculpta (Kendall's $\tau$ values $=0.31,0.23$ and 0.23 respectively; Supplementary Table 3$)$. Axis 1 was negatively related to Fire $(-0.85 \pm 0.25$, $t=-3.365, \mathrm{P}=0.001$; Fig. 4 ), indicating that rhino foraging sites had lower fire frequencies than randomly selected background plots. The next best model predicting NMDS axis 1 included both Fire and Slope, but was inferior according to model selection $(\triangle \mathrm{AIC}=7.2)$ Indicator analysis identified 18 plant species with statistically significant associations between background vegetation and rhino foraging plots (Table 3). One species, the grass Chloris gayana, was statistically associated with background plots. The other 17 species, largely woody forbs, shrubs and trees $(n=13)$, were statistically associated with rhino foraging plots.

Forage selectivity Within foraging stations, nine of 56 species were positively selected by rhinos; one species
(Indigofera volkensii) was significantly consumed but with a standard error that included zero and the other 47 species were avoided (Fig. 3). Of the species selectively consumed, four were herbs or trees of the family Leguminosae and the others were robust suffruticose forbs (e.g. Achyranthes aspera and Justicia betonica) or woody shrubs (e.g. Abutilon grandiflorum, Hibiscus sp. and Ziziphus abyssinica). Of the nine plant species preferred by rhinos, eight were also identified as statistically associated with rhino presence from the indicator analysis (Table 3).

Diet selection Rhino dung samples contained sufficient DNA to identify 72 MOTUs. Of these, 39 taxa occurred at a taxonomic sample frequency $\geq 4$ and of those, 14 occurred at a relative read abundance $>2 \%$ (Supplementary Table 4 ). For these 14 species, seven were selectively consumed in the rhino foraging plots (Table 3 ) and 13 were amongst the indicator species (Table 3). The species composition of the dung samples, the indicator species and the Manly selectivity index therefore showed considerable agreement concerning the plant species preferred by foraging black rhinos. Notable of the 14 species in dung were plants of the family Leguminosae, which accounted for the top four species, with relative read abundances of 9.4-12.6\% (Supplementary Table 4).

Fire effects on vegetation Two equivalent models predicted the relative abundance of the 17 indicator species: one with only Fire $(\triangle \mathrm{AIC}=0.0)$ and one with Fire and TWI as main effects $(\triangle \mathrm{AIC}=1.1)$. The next best model included only TWI but was not considered further $(\triangle \mathrm{AIC}=4.5)$. In the best model, the abundance of rhino indicator species decreased with Fire across all plots $(-1.97 \pm 0.85, t=-2.31, \mathrm{P}=0.024)$. In the next best model, rhino indicator species also decreased with Fire $(-1.69 \pm 0.84, t=-2.01, \mathrm{P}=0.048)$ and increased with TWI $(0.13 \pm 0.06, t=2.22, \mathrm{P}=0.029)$.

\section{Discussion}

Serengeti rhinos demonstrated strong preferences for a relatively small selection of woody shrubs and forbs, particularly those in the Leguminosae family. However, the novelty of our study lies in the relationships among fire, spatial occupancy in the landscape and foraging selectivity confirmed through observations and faecal DNA analyses. Our results show that (1) rhinos select habitats that burn infrequently, (2) the plant composition of foraging stations used by rhinos is associated with low fire frequencies and (3) the abundance of plant species preferred by rhinos decreases with increasing fire frequency. To the best of our knowledge, this is the first study to demonstrate potentially negative effects of fire 


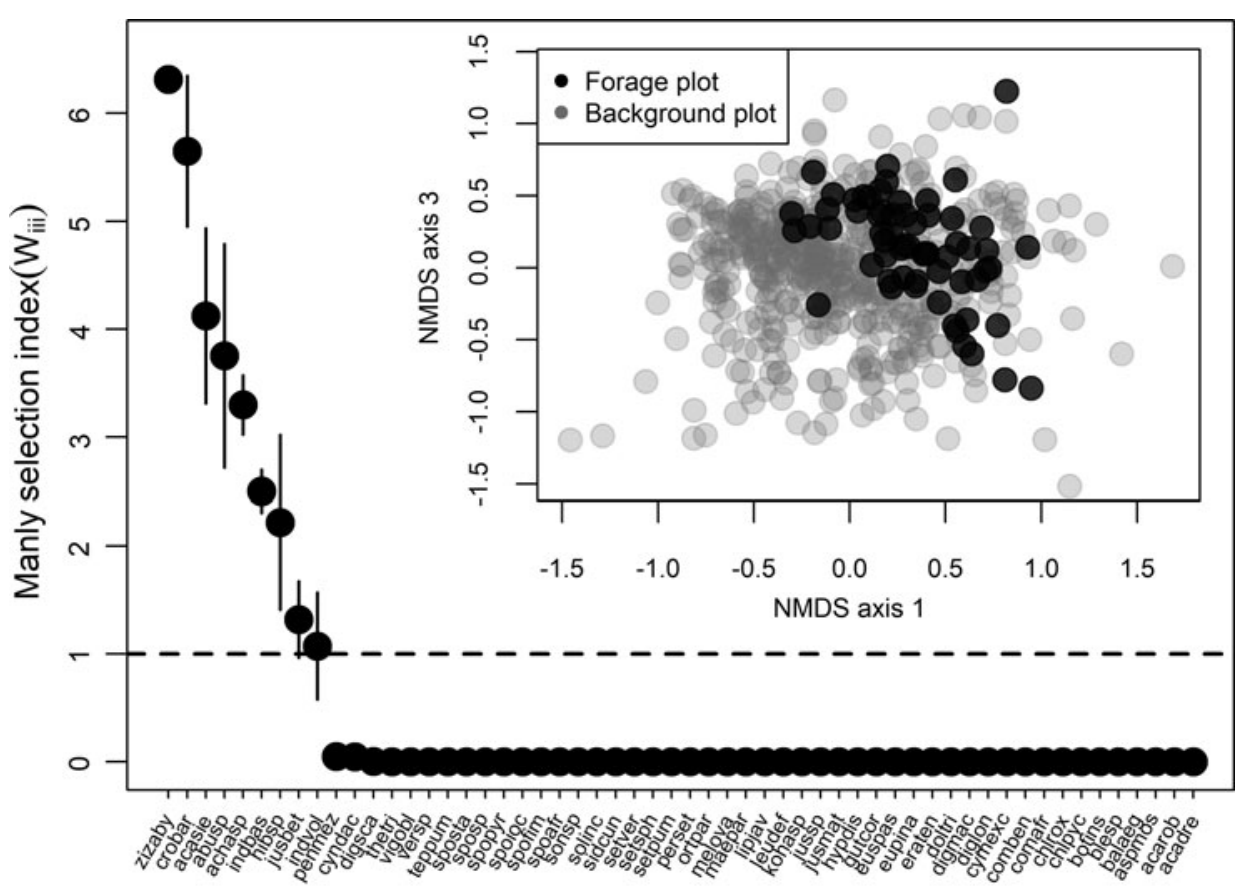

Species code
FIG. 3 Rank Manly selectivity index \pm SD $\left(W_{i i i}\right)$ for all species (Supplementary Table 3 ) in rhino foraging plots. $W_{i i i}>_{1}$ are statistically selected, $<1$ are avoided and $W_{i i i}=1$ are species consumed in direct proportion to their availability. Inset shows NMDS results for plant species community data for randomly selected background plots (light grey dots) and for rhino forage plots (black dots). Axes 1 and 3 best represented the differences between background and forage plots. on the foraging and ranging activities of this Critically Endangered species.

\section{Habitat selectivity}

Fire, plant productivity and topography were important predictors of rhino habitat selection. As precipitation is uniform across the study area, topography and soils are the major determinant of variation in plant productivity and thus rhino habitat use. For example, slopes and ephemeral drainages receive greater amounts of runoff and have deeper soils than upslope savannahs. Woody plants exploit these soils, obtaining deeper sources of water, thus driving high productivity of the broad-leaved/woody vegetation favoured by rhinos. The microclimatic conditions in low-lying drainages encourage growth of vegetation preferred by rhinos, which further suppresses fire by modifying the soil, altering grazing frequency and reducing evapotranspiration (e.g. Vetaas, 1992).

\section{Plant species selectivity}

Plants highly preferred by rhinos tended to be woody or suffruticose forbs with upright growth forms. Of the five legumes occurring in foraging plots but not selected by rhinos (Fig. 3), three are prostrate vines that grow below the grass canopy (Dolichos, Tephrosia and Vigna; TMA, pers. obs.) and the remaining two are trees defended either by ants (Acacia drepanolobium) or secondary compounds
(Acacia robusta). Thus, within foraging stations, Serengeti black rhinos consumed plants that were accessible and not heavily defended.

Black rhinos in East Africa (Goddard, 1968; Goddard, 1970; Oloo et al., 1994) and South Africa (Emslie \& Adcock, 1994a; Ganqa et al., 2005; Buk \& Knight, 2010) consume a wide variety of plants but tend to rely heavily on few species, notably leguminous trees and shrubs. In Itala game reserve, South Africa, $86 \%$ of browsed plants were from few species, including the highly available Acacia nilotica, Acacia karoo and Dichrostachys cinerea and highly preferred Cassine transvaalensis, Rhus gueinzii and Acacia gerrardii (Kotze \& Zacharias, 1993). In the Massai Mara ecosystem of southern Kenya, rhinos were highly selective for the woody herb Solanum incanum, low growing trees, such as Dichrostachys cinerea, Acacia hockii, Acacia brevispica and Croton dichogamus, and the shrub Maerua edulis (Mukinya, 1977). Solanum sp. was abundant in Serengeti dung samples (relative read abundance $=8.3$; Supplementary Table 4 ) but was not consumed by rhinos in the foraging plots, perhaps because Solanum is unpalatable in large quantities (e.g. Goddard, 1968) and only selected when other species, such as highly preferred leguminous forbs and shrubs, are unavailable.

Given their large body size and hind-gut digestion, one might expect black rhinos to tolerate a variety of forage qualities. However, chemical analyses of preferred, indifferent and rejected plant species suggested that rhinos do not select forage to maximize digestibility or nutrient intake (van Lieverloo et al., 2009). Rhinos cannot tolerate plants heavily 


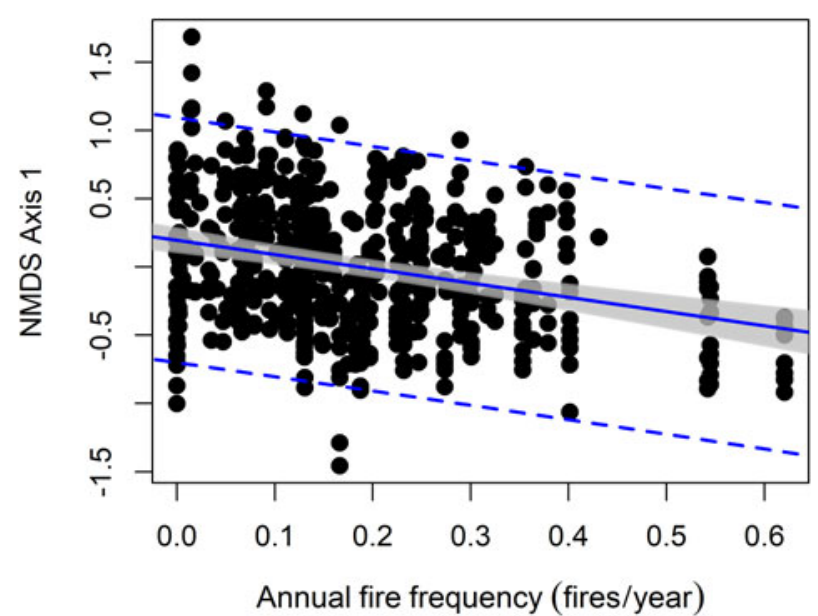

FIG. 4 Negative linear relationship between NMDS axis 1 of the ordination and fire frequency. Solid line shows the best fit ordinary least squares for the relationship between NMDS axis 1 and fire frequency; dashed lines show $95 \%$ prediction intervals and the grey region shows $95 \%$ confidence intervals for the mean.

TABLE 3 List of plant species that were identified with indicator analysis as being statistically associated with rhino foraging plots as compared to background vegetation plots.

\begin{tabular}{|c|c|c|c|}
\hline Species & Plant functional type & Stat $^{1}$ & $\mathrm{P}$ \\
\hline \multicolumn{4}{|l|}{ Background plots } \\
\hline Chloris gayana & Grass & 0.427 & 0.013 \\
\hline \multicolumn{4}{|l|}{ Forage plots } \\
\hline Indigofera basiflora ${ }^{\star}$ & Leguminous forb & 0.787 & 0.001 \\
\hline Bothriochloa insculpta* & Grass & 0.577 & 0.001 \\
\hline Hibiscus sp. ${ }^{\star}$ & Shrub & 0.557 & 0.001 \\
\hline Acacia sieberiana ${ }^{\star}$ & Leguminous tree & 0.534 & 0.001 \\
\hline Dolichos trilobus ${ }^{\star}$ & Leguminous forb & 0.516 & 0.001 \\
\hline Digitaria abyssinica* & Grass & 0.441 & 0.001 \\
\hline Sporobolus africanus* & Grass & 0.433 & 0.001 \\
\hline Achyranthes aspera ${ }^{\star}$ & Forb & 0.419 & 0.001 \\
\hline Indigofera volkensii ${ }^{\star}$ & Leguminous forb & 0.410 & 0.002 \\
\hline Balanites aegyptiaca & Tree & 0.353 & 0.001 \\
\hline Acacia drepanolobium ${ }^{*}$ & Leguminous tree & 0.316 & 0.002 \\
\hline Abutilon sp. ${ }^{\star}$ & Forb & 0.307 & 0.002 \\
\hline Cymbopogon excavatus ${ }^{*}$ & Grass & 0.290 & 0.040 \\
\hline Crotalaria barkae $^{\star}$ & Leguminous forb & 0.276 & 0.001 \\
\hline Orthosiphon parvifolius & Forb & 0.258 & 0.013 \\
\hline Setaria verticillata & Grass & 0.251 & 0.002 \\
\hline Ziziphus abyssinica & Shrub & 0.177 & 0.013 \\
\hline Sonchus sp. & Forb & 0.163 & 0.039 \\
\hline
\end{tabular}

${ }^{1}$ The association statistic of each species by plot type, with probability estimated from permutation tests. Species in bold were preferred by rhinos in forage selectivity analyses (Manly selectivity index $>_{1}$ ).

${ }^{*}$ Found in faecal samples using DNA metabarcoding.

protected by volatile secondary compounds such as alkaloids and phenols (Muya \& Oguge, 2000). Taken together, these studies suggest that rhino selectivity may be aimed at reducing intake of secondary chemical compounds.

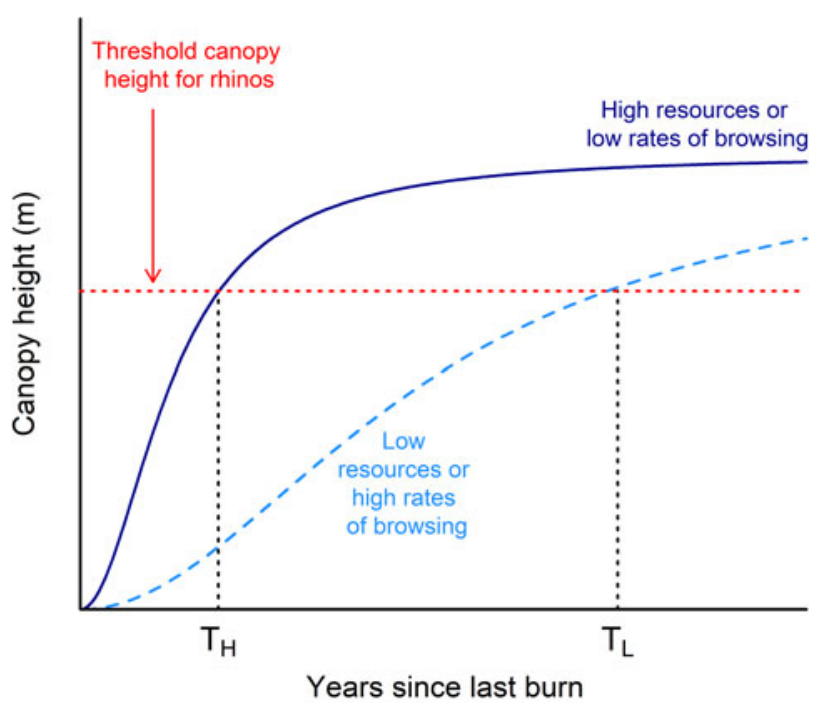

FIG. 5 Theoretical relationship between savannah tree canopy and time since last fire for two hypothetical sites, one high resources, or low rates of browsing pressure, and one low resources, or high rates of browsing pressure on woody plants. A threshold at which forage availability drops significantly for black rhinos is shown as a horizontal dotted line; the intersection between this threshold and the curves indicates the predicted time until rhinos are excluded from foraging at a high resource/ low browsing $\left(T_{\mathrm{H}}\right)$ and low resource/high browsing site $\left(T_{\mathrm{L}}\right)$. Modified from Lehmann et al., 2011.

\section{Responses to burning}

Fire is a powerful management tool that improves foraging opportunities for many African savannah herbivores (e.g. Archibald et al., 2005; Trollope 2011). In Kruger National Park, high fire frequency and short fire return intervals lead to increased foliar nitrogen and decreased non-structural carbohydrate defense compounds in Colophospermum mopane (Ferwerda et al., 2006), presumably increasing palatability for browsers. In contrast, if fire eliminates preferred plants it may have a net negative effect on browsers. Therefore, the effect of fire on browser foraging may depend on the balance between improving foliar quality of plants that regrow after fire and eliminating plants that are preferred by browsers.

For black rhinos, some have noted they prefer unburnt (or not seriously burnt) vegetation (e.g. Mukinya, 1977), whereas others have noted they consume burnt vegetation (Goddard, 1968; Emslie \& Adcock, 1994a), perhaps because of the high salt content. Although individual animals may eat burnt plants, or be found in burnt areas, rhino habitat preference and forage consumption is negatively associated with frequent fire in the Serengeti. We acknowledge that a negative relationship could arise because rhinos (1) directly avoid frequently burnt vegetation or (2) select habitat because of other features and the relationship with fire is one that emerges indirectly. Whether the relationship is direct or indirect, the implication is that rhinos do not benefit 
from frequent fire and it may have negative consequences for rhino foraging and ranging behavior. For example, when rhinos increase their search area to find food, energy expenditure increases as does the potential for greater encounter rates with humans and natural predators (PMN, pers. obs.).

\section{Management implications}

Rhinos face threats from poaching (Emslie, 2012), loss of population genetic diversity (Mills et al., 2006), unpalatable invasive species (Murphy et al., 2013), changing vegetation and habitat quality (Reid et al., 2007) and an expanding human population (Sinclair et al., 2008), making their conservation more challenging than ever. A study that mapped habitat suitability and poaching risk in the Serengeti suggested rainfall and elevation best predict successful black rhino reintroduction (Metzger et al., 2007). Our data suggest that fire history, NDVI and the proportion of available shrubs and legumes in the understory be explicitly considered in determining black rhino habitat suitability.

Kotze \& Zacharias (1993) and Emslie \& Adcock (1994b) concluded that management actions encouraging a switch from open woodland to closed canopy forest would negatively affect black rhinos. Their explicit recommendation was clearing or thinning of tall vegetation and frequent burning at a low to moderate intensity, the implication being that tree removal and fire maintain open woodland habitat and fire suppression encourages a detrimental switch to closed canopy woodland. In theory, regions with abundant resources or low rates of woody plant consumption should have a shorter time until canopy closure relative to regions with low resources or high rates of woody plant consumption (Lehmann et al., 2011). Thus, an important implication is that the effects of altered fire regimes on rhino habitat quality and foraging may be context specific, depending on timing and likelihood of canopy closure in the absence of burning (Fig. 5). In the Moru area, even where fire frequencies are low, woody vegetation does not form closed-canopy woodlands that reduce rhino foraging opportunities. Perhaps because of the large browser community in the Serengeti, and elephants in particular, vegetation is maintained in shrub-like growth forms and well within the browse line of black rhinos. Others have suggested negative interactions between elephants and rhinos (Birkett, 2002). Becasue of recent increases in elephant populations in the Serengeti and their disproportionate negative effect on tree survival (Morrison et al., 2016), this should be tested explicitly.

Given the importance of pyrodiversity (i.e. fire size, timing, intensity; sensu Hempson et al., 2018) for influencing African bird and mammal richness (Beale et al., 2018), future research is required to understand how different fire characteristics, other than frequency, influence black rhino foraging, movements and habitat utilization. For example, large, intense fires may be particularly pernicious if they remove large quantities of woody biomass, whereas small, cooler fires, even if they burn frequently, may not eliminate preferred plant species.

A management recommendation resulting from our work is to implement controlled experiments that determine how fire characteristics (frequency, size, timing and intensity) effect the stability of woody cover (Fig. 5) and the abundance of trees, shrubs and legumes that dominate rhino diets in the Serengeti. By highlighting the potential effects of fire on black rhino ecology we hope to improve chances of successful reestablishment in one of the last great natural sanctuaries for the Critically Endangered black rhino.

Acknowledgements Funding was provided by National Geographic grant 9034-11, NSF-DEB-1145861 and NSF-BCS-1461728 to TMA. BJG, ER, FF and JDMS were supported by the European Union's Horizon 2020 research and innovation programme, AfricanBioServices grant 641918. We thank Serengeti chief park warden W. Mwakilema, Tanzanian National Parks and the Tanzania Wildlife Research Institute for providing permits and facilitating our research. J. Sarakiya and K. Magige assisted with field work.

Author contributions Data collection: TMA, PMN and MLN; data analysis: TMA, PMN, JDMS, DG, FF and BJG; creation of the fire map for the Serengeti: DG; writing: TMA and PMN. All authors conceived the ideas and methods and contributed to the text.

\section{Conflicts of interest None.}

Ethical standards This research complied with the Oryx Code of Conduct for authors.

\section{References}

Anderson, T.M., Ritchie, M.E., Mayemba, E., Eby, S., Grace, J.B. \& MCNAUGhTON, S.J. (2007) Forage nutritive quality in the Serengeti ecosystem: the roles of fire and herbivory. American Naturalist, 170, 343-357.

Archibald, S., Bond, W.J., Stock, W.D. \& Fairbanks, D.H.K. (2005) Shaping the landscape: fire-grazer interactions in an African savanna. Ecological Applications, 15, 96-109.

Bailey, D.W., Gross, J.E., Laca, E.A., Rittenhouse, L.R., Coughenour, M.B., Swift, D.M. \& Sims, P.L. (1996) Mechanisms that result in large herbivore grazing distribution patterns. Journal of Range Management, 49, 386-400.

Bates, D., Maechler, M., Bolker, B. \& Walker, S. (2015) Fitting linear mixed-effects models using Ime4. Journal of Statistical Software, 67, 1-48.

Beale, C.M., Courtney-Mustaphi, C.J., Morrison, T.A., Archibald, S., Anderson, T.M., Dobson, A.P. et al. (2018) Pyrodiversity interacts with rainfall to increase bird and mammal richness in African savannas. In press, Ecology Letters, 21, 557-567.

BirketT, A. (2002) The impact of giraffe, rhino and elephant on the habitat of a black rhino sanctuary in Kenya. African Journal of Ecology, 40, 276-282.

Borner, M. (1981) Rhino disaster in Tanzania. Oryx, 16, 59-66. Boyce, M.S., Mao, J.S., Merrill, E.H., Fortin, D., Turner, M.G., FryXell, J. \& TurChin, P. (2003) Scale and heterogeneity in habitat selection by elk in Yellowstone National park. Ecoscience, 10, 421-431. 
Buk, K.G. \& KNIGHT, M.H. (2010) Seasonal diet preferences of black rhinoceros in three arid South African national parks. African Journal of Ecology, 48, 1064-1075.

Burnham, K.P. \& Anderson, D.R. (2002) Model Selection and Multimodel Inference: A Practical Information-Theoretic Approach. 2nd edition. Springer Verlag, New York, USA.

Calenge, C. (2006) The package adehabitat for the $R$ software: a tool for the analysis of space and habitat use by animals. Ecological Modelling, 197, 516-519.

Dalle, G., Maass, B.L. \& Isselstein, J. (2006) Encroachment of woody plants and its impact on pastoral livestock production in the Borana lowlands, southern Oromia, Ethiopia. African Journal of Ecology, 44, 237-246.

De Cáceres, M.D. \& Legendre, P. (2009) Associations between species and groups of sites: indices and statistical inference. Ecology, 9o, 3566-3574.

De Cáceres, M.D., Legendre, P. \& Moretti, M. (2010) Improving indicator species analysis by combining groups of sites. Oikos, 119, 1674-1684.

Dempewolf, J., Trigg, S., DeFries, R.S. \& Eby, S. (2007) Burned-area mapping of the Serengeti-Mara region using MODIS reflectance data. IEEE Geoscience and Remote Sensing Letters, 4, 312-316.

DE Wit, H.A. (1978) Soils and Grassland Types of the Serengeti Plain (Tanzania): Their Distribution and Interrelations. $\mathrm{PhD}$ thesis. Agricultural University, Wageningen, The Netherlands.

Emslie, R. (2012) Diceros bicornis. The IUCN Red List of Threatened Species 2012: e.T6557A16980917. Http://dx.doi.org/10.2305/IUCN. UK.2012.RLTS.T6557A16980917.en.

Emslie, R.H. \& ADсоск, K. (1994a) Managing black rhinoceros. In Proceedings of the Symposium Rhinos as Game Ranch Animals. (eds B.L. Penzhorn \& N.P. Kriek), pp. 100-107. SAVA Wildlife Group, Onderstepoort.

Emslie, R.H. \& Adсоск, K. (1994b) Feeding ecology of black rhinoceros. In Proceedings of the Symposium Rhinos as Game Ranch Animals (eds B.L. Penzhorn \& N.P. Kriek) pp. 65-81. SAVA Wildlife Group, Onderstepoort.

Ferwerda, J.G., Siderius, W., van Wieren, S.E., Grant, C.C., Peel, M., Skidmore, A.K. \& Prins, H.H.T. (2006) Parent material and fire as principle drivers of foliage quality in woody plants. Forest Ecology and Management, 231, 178-183.

Frame, G.W. (1980) Black rhinoceros (Diceros bicornis L.) subpopulation on the Serengeti Plains, Tanzania. African Journal of Ecology, 18, 155-166.

Fryxell, J.M., Wilmshurst, J.F. \& Sinclair, A.R. (2004) Predictive models of movement by Serengeti grazers. Ecology, 85, 2429-2435.

GanQA, N.M., Scogings, P.F. \& RaAts, J.G. (2005) Diet selection and forage quality factors affecting woody plant selection by black rhinoceros in the great fish river reserve, South Africa. South African Journal of Wildlife Research, 35, 77-83.

Gillies, C.S., Hebblewhite, M., Nielsen, S.E., Krawchuk, M.A., Aldridge, C.L., Frair, J.L. et al. (2006) Application of random effects to the study of resource selection by animals. Journal of Animal Ecology, 75, 887-898.

Goddard, J. (1968) Food preferences of two black rhinoceros populations. East African Wildlife Journal, 6, 1-18.

GodDARD, J. (1970) Food preferences of black rhinoceros in the Tsavo National Park. East African Wildife Journal, 8, 145-161.

Göttert, T., Schöne, J., Zinner, D., Hodges, J.K. \& Böer, M. (2010) Habitat use and spatial organisation of relocated black rhinos in Namibia. Mammalia, 74, 35-42.

Hempson, G.P., Parr, C.L., Archibald, S., Anderson, T.M., Mustaphi, C.J.C., Dobson, A.P. et al. (2018) Continent-level drivers of African pyrodiversity. Ecography, 41, 889-899.
Hijmans, R.J. (2016) raster: Geographic Data Analysis and Modeling. R package version 2.5-8. Https://CRAN.R-project.org/package=raster [accessed o8 August 2018].

Holdo, R.M., Holt, R.D. \& Fryxell, J.M. (2009) Grazers, browsers, and fire influence the extent and spatial pattern of tree cover in the Serengeti. Ecological Applications, 19, 95-109.

Hopcraft, J.G.C., Anderson, T.M., Pérez-Vila, S., Mayemba, E. \& OlFF, H. (2012) Body size and the division of niche space: food and predation differentially shape the distribution of Serengeti grazers. Journal of Animal Ecology, 81, 201-213.

JAGER, T.J. (1982) Soils of the Serengeti Woodlands, Tanzania. PhD thesis. Agricultural University, Wageningen, The Netherlands.

Jarvis, A., Reuter, H.I., Nelson, A. \& Guevara, E. (2008) SRTM 90 Digital Elevation Data, Version 4. Http://srtm.csi.cgiar.org [accessed March 2015].

Johnson, C.J., Seip, D.R. \& Boyce, M.S. (2004) A quantitative approach to conservation planning: using resource selection functions to map the distribution of mountain caribou at multiple spatial scales. Journal of Applied Ecology, 41, 238-251.

Kartzinel, T.R., Chen, P.A., Coverdale, T.C., Erickson, D.L., Kress, W.J., Kuzmina, M.L. et al. (2015) DNA metabarcoding illuminates dietary niche partitioning by African large herbivores. Proceedings of the National Academy of Sciences, 112, 8019-8024.

Kotze, D.C. \& Zacharias, P.J.K. (1993) Utilization of woody browse and habitat by the black rhino (Diceros bicornis) in western Itala game reserve. African Journal of Range and Forage Science, 10, 36-40.

Lehmann, C.E., Archibald, S.A., Hoffmann, W.A. \& Bond, W.J. (2011) Deciphering the distribution of the savanna biome. New Phytologist, 191, 197-209.

Lehner, B., Verdin, K. \& Jarvis, A. (2006) HydroShEDS Technical Documentation. World Wildlife Fund US, Washington, DC, USA. Http://hydrosheds.cr.usgs.gov [accessed January 2010].

Manly, B.F.J., McDonald, L.L., Thomas, D.L., McDonald, T.L. \& Erickson, W.P. (2002) Resource Selection by Animals. 2nd edition. Kluwer Academic Publishers, Dordrecht, The Netherlands.

Metzger, K.L., Sinclair, A.R.E., Campbell, K.L., Hilborn, R., Hopcraft, J.G.C., Mduma, S.A.R. \& Reich, R.M. (2007) Using historical data to establish baselines for conservation: The black rhinoceros (Diceros bicornis) of the Serengeti as a case study. Biological Conservation, 139, 358-374.

McCune, B., Grace, J.B. \& Urban, D.L. (2002) Analysis of Ecological Communities. MjM software design, Gleneden Beach, USA.

Mills, A., Morkel, P., Amiyo, A., Runyoro, V., Borner, M. \& THIRGOOD, S. (2006) Managing small populations in practice: black rhino Diceros bicornis michaeli in the Ngorongoro Crater, Tanzania. Oryx, 40, 319-323.

Mitchell, M.S. \& Powell, R.A. (2012) Foraging optimally for home ranges. Journal of Mammalogy, 93, 917-928.

Morrison, T.A., Holdo, R.M. \& Anderson, T.M. (2016) Elephant damage, not fire or rainfall, explains mortality of overstorey trees in Serengeti. Journal of Ecology, 104, 409-418.

MukinyA, J.G. (1977) Feeding and drinking habitats of the black rhinoceros in Masai Mara game reserve. East African Wildlife Journal, 15, 125-138.

Murphy, S.T., Subedi, N., Jnawali, S.R., Lamichhane, B.R., UpAdHyAY, G.P., Kock, R. \& AmIN, R. (2013) Invasive mikania in Chitwan National Park, Nepal: the threat to the greater one-horned rhinoceros Rhinoceros unicornis and factors driving the invasion. Oryx, 47, 361-368.

MUya, S.M. \& OGUGE, N.O. (2000) Effects of browse availability and quality on black rhino (Diceros bicornis michaeli Groves 1967) diet in Nairobi National Park, Kenya. African Journal of Ecology, 38, 62-71. Northrup, J.M., Hooten, M.B., Anderson, C.R. \& Wittemyer, G. (2013) Practical guidance on characterizing availability in resource 
selection functions under a use-availability design. Ecology, 94, 1456-1463.

Odendaal-Holmes, K., Marshal, J.P. \& Parrini, F. (2014) Disturbance and habitat factors in a small reserve: space use by establishing black rhinoceros (Diceros bicornis). South African Journal of Wildlife Research, 44, 148-160.

Oloo, T.W., BRet T, R. \& Young, T.P. (1994) Seasonal variation in the feeding ecology of the black rhinoceros (Diceros bicornis L.) in Laikipia, Kenya. Journal of African Ecology, 32, 142-157.

Owen-Smith, N., Fryxell, J.M. \& Merrill, E.H. (2010) Foraging theory upscaled: the behavioural ecology of herbivore movement. Philosophical Transactions of the Royal Society of London B: Biological Sciences, 365, 2267-2278.

Oksanen, J., Blanchet, F.G., Friendly, M., Kindt, R., Legendre, P., McGlinn, D. et al. (2017) vegan: Community Ecology Package. R package version 2.4-4. Https://CRAN.R-project.org/package=vegan

Parrini, F. \& OWen-Smith, N. (2010) The importance of post-fire regrowth for sable antelope in a Southern African savanna. African Journal of Ecology, 48, 526-534.

Pusparini, W., Sievert, P.R., Fuller, T.K., Randhir, T.O. \& ANDAYANi, N. (2015) Rhinos in the parks: an island-wide survey of the last wild population of the Sumatran rhinoceros. PLoS ONE, 10, eo136643.

R Development Core Team (2017) R: A Language and Environment for Statistical Computing. R Foundation for Statistical Computing, Vienna, Austria. Http://www.R-project.org [accessed 28 September 2017].

Reid, C., Slotow, R., Howison, O. \& Balfour, D. (2007) Habitat changes reduce the carrying capacity of Hluhluwe-Umfolozi Park, South Africa, for critically endangered black rhinoceros Diceros bicornis. Oryx, 41, 247-254

Searle, K.R., Thompson Hobbs, N. \& Shipley, L.A. (2005) Should I stay or should I go? Patch departure decisions by herbivores at multiple scales. Oikos, 111, 417-424.
Shafer, A., Northrup, J.M., White, K.S., Boyce, M.S., Côté, S.D. \& Coltman, D.W. (2012) Habitat selection predicts genetic relatedness in an alpine ungulate. Ecology, 93, 1317-1329.

Sinclair, A.R.E., Hopcraft, J.C.G., Olff, H., Mduma, S.A.R., Galvin, K.A. \& Sharam, G.J. (2008) Historical and future changes to the Serengeti ecosystem. In Serengeti III: Human Impacts on Ecosystem Dynamics (eds A.R.E. Sinclair, C. Packer, S.A. R. Mduma \& J.M. Fryxel), pp. 7-46. University of Chicago Press, Chicago, USA.

Sörensen, R., Zinko, U. \& Seibert, J. (2006) On the calculation of the topographic wetness index: evaluation of different methods based on field observations. Hydrology and Earth System Sciences Discussions, 10, 101-112.

Trollope, W.S.W. (2011) Personal perspectives on commercial versus communal African fire paradigms when using fire to manage rangelands for domestic livestock and wildlife in southern and East African ecosystems. Fire Ecology, 7, 57-73.

Valeix, M., Loveridge, A.J., Chamaillé-Jammes, S., Davidson, Z., Murindagomo, F., Fritz, H. \& Macdonald, D.W. (2009) Behavioral adjustments of African herbivores to predation risk by lions: spatiotemporal variations influence habitat use. Ecology, 90, 23-30.

van Lieverloo, R.J., Schuiling, B.F., De Boer, W.F., Lent, P.C., De Jong, C.B., Brown, D. \& Prins, H.H. (2009) A comparison of faecal analysis with backtracking to determine the diet composition and species preference of the black rhinoceros (Diceros bicornis minor). European Journal of Wildlife Research, 55, 505-515.

VetaAs, O.R. (1992) Micro-site effects of trees and shrubs in dry savannas. Journal of Vegetation Science, 3, 337-344.

Vermote, E. \& Wolfe, R. (2015) MODogGQ MODIS/Terra Surface Reflectance Daily L2G Global $250 m$ SIN Grid Voo6 [Data set]. NASA EOSDIS LP DAAC. Http://doi.org/10.5067/MODIS/MODo9GQ. 006 [accessed 23 May 2016].

White, F. (1983) The Vegetation of Africa. UNESCO, Paris, France. 